\title{
Slow growth in vitro culture for conservation of Chilotanum potato germplasm
}

\author{
Manuel Muñoz ${ }^{1 *}$, Oscar Díaz ${ }^{2}$, Waleska Reinún², Annelore Winkler ${ }^{1}$, and Roberto Quevedo² \\ ${ }^{1}$ Instituto de Investigaciones Agropecuarias, INIA Remehue, Ruta 5 Sur, km 8 Norte, Osorno, Chile. \\ "Corresponding author (manuel.munozd@inia.cl). \\ ${ }^{2}$ Universidad de Los Lagos, Departamento de Acuicultura y Recursos Agroalimentarios, Campus Osorno. Fuchslocher 1305, Osorno, Chile.
}

Received: 24 June 2018; Accepted: 3 November 2018; doi:10.4067/S0718-58392019000100026

\begin{abstract}
To keep potato (Solanum tuberosum L.) germplasm accessions disease-free and available for use, these are conserved as in vitro microplants under tissue culture conditions. The management of in vitro plants is labor intensive due to the necessity of periodic transferring of explants to new containers and fresh medium (sub culturing). The effectiveness of MS medium supplemented with sorbitol or mannitol in conservation of potato germplasm corresponding to different genotypes from Chilean native landraces (Chilotanum group) was investigated. Growth curves for modelling, describing and predicting shoot elongation of in vitro potato plants through the time in different culture media were developed as a tool to plan subculture labor for refreshing explants to new media. In MS medium without osmotic active compounds the rate of shoot elongation $(\mathrm{k})$ was $1.12-1.45 \mathrm{~cm} \mathrm{wk}^{-1}$ with $0 \%$ mortality. In media supplemented with 20,40 , and $60 \mathrm{~g}$ $\mathrm{L}^{-1}$ sorbitol, $\mathrm{k}$ value ranged between $0.58-0.35,0.42-0.27$ and $0.09-0.05 \mathrm{~cm} \mathrm{wk}^{-1}$, respectively. Mortality was $0 \%, 13 \%$, and $26 \%$ for such treatments. In case of mannitol, $\mathrm{k}$ value ranged between $0.14-0.25,0.065-0.11$ and $0.042-0.068 \mathrm{~cm} \mathrm{wk}^{-1}$ with $3 \%, 6 \%$, and $26 \%$ mortality for 20,40 , and $60 \mathrm{~g} \mathrm{~L}^{-1}$, respectively. These data can be used to predict shoot elongation rate in different media that provide several alternatives of speed of growth. The information allows to design an adequate strategy for organizing the work in a potato germplasm bank of S. tuberosum, Chilotanum group.
\end{abstract}

Key words: Growth modelling, mannitol, potato germplasm, Solanum tuberosum, sorbitol, tissue culture.

\section{INTRODUCTION}

Species diversity has been shown to stimulate productivity, stability, ecosystem services, and resilience in natural and in agricultural ecosystems. Likewise, variation in food species contributing to diet has been associated with nutritional adequacy and food security. Because crop development efforts rely on the utilization of genetic resources, it is a policy imperative to ensure the conservation of and access to as wide a range of genetic diversity within these global crops as possible, along with the genotypic and phenotypic information necessary to effectively use these resources (Khoury et al., 2014).

Potato (Solanum tuberosum L.) is the most important tuber crop worldwide, continuing to gain significance in temperate and tropical regions as a source of carbohydrates, vitamins, and minerals as well as for industrial purposes. The crop is susceptible to a wide range of biotic stresses, in particular fungal diseases and pests. A relatively low historical influx of variation has led to a genetic bottleneck within potato cultivars. Thus, the development of potato varieties with novel genetic diversity is expected to improve resistance to biotic and abiotic constraints (CastañedaÁlvarez et al., 2015).

South American potato landraces are still highly diverse with a variety of tuber shapes, skin, and flesh colors. Depending on taxonomic treatment, S. tuberosum has been divided into the sub-species andigenum and tuberosum (Hawkes, 1990) 
or divided into cultivar groups: Andigenum (including diploids, triploids, and tetraploids) and Chilotanum (tetraploids) (Spooner et al., 2014). The Chilotanum group corresponds to lowland tetraploid Chilean landraces with a geographical origin in Chiloé and the Chonos Archipelago. Hawkes (1990) proposed that it evolved from Andigenum and was introduced into southern Chile followed by adaptation to longer day lengths. Near 300 Chilean landraces have been reported and documented in catalogues and scientific articles (Contreras and Castro, 2008; Muñoz et al., 2016). The diversity of the Chilotanum group in Chile is currently spread over different farmer communities in southern Chile, germplasm banks of the Institute of Agricultural Research (INIA), universities and private collections (Muñoz et al., 2016). As one source of genetic variation, potato breeding programs can make use of this germplasm to improve and develop new varieties of potatoes, therefore, emphasis on improving the conservation technologies of potato is a key step in ensuring the long-term availability of genetic resources of this critical crop.

Elite parental lines/clones of potato are thus maintained through vegetative propagation rather than as true (botanical) seeds because sexual reproduction leads to segregation of the genotype. In order to keep the potato germplasm accessions disease-free, these are conserved as in vitro propagated microplants under tissue culture conditions. The management of in vitro plants is labor intensive due to the necessity of transferring explants to new containers and fresh medium after 1 to 2-mo (sub culturing), due to the depletion of the nutrients from medium and completion of the space required for the growing plant inside the container. The frequency of sub-culturing is reduced by growing the microplants on MS medium (Murashige and Skoog, 1962) supplemented with growth retardants or osmotic stress inducing polyols and incubating them under low temperature, low light intensity, and varied photoperiod (Gopal and Chauhan, 2010).

In the present study, the effectiveness of MS medium supplemented with sorbitol or mannitol in conservation of potato germplasm corresponding to different genotypes from Chilean native landraces (Chilotanum group) was investigated. Several works have been reported researching the in vitro culture in presence of growth retardants for potatoes belonging to Andigenum group or modern varieties (Gopal and Chauhan, 2010; Shahriyar et al., 2015; Mohapatra and Batra, 2017) but scarce literature is found about the performance of Chilean landraces of Chilotanum group in presence of osmotically active compounds during in vitro culture. In this work, growth curves for modelling, describing and predicting shoot elongation of in vitro potato plants through the time in different culture media are developed as a tool to plan subculture labor for refreshing explants to new media or preparing plants for ex vitro acclimatization.

\section{MATERIALS AND METHODS}

\section{Plant material}

Three genotypes were used in the study, named CH6-13 Sofía (IN), R12-15 Clon 18 Amarillo (CO) and CH9-1 Ojos Sarcos de Cahuala (NA) from the germplasm bank of the Plant Tissue Culture Laboratory at the Instituto de Investigaciones Agropecuarias (INIA), located in Remehue, $8 \mathrm{~km}$ to the north of Osorno, Chile. These genotypes were kept for in vitro conservation using the Murashige and Skoog (MS) medium with $27.5 \mathrm{~g} \mathrm{~L}^{-1}$ sucrose and solidificated with $7.5 \mathrm{~g} \mathrm{~L}^{-1}$ agar. This plant material was previously introduced into the germplasm bank through the extraction of sprouts tubers and then introduced within the previously mentioned culture medium. Thereafter, potato plants were obtained.

A total of 80 in vitro free virus plantlets were required for each genotype in this investigation. The plantlets were obtained from micropropagation of the genotype plants that were already available in the germplasm bank. For this purpose, the same culture media was prepared, which consisted of $4.43 \mathrm{~g} \mathrm{~L}^{-1} \mathrm{MS}$ medium and $27.5 \mathrm{~g} \mathrm{~L}^{-1}$ sucrose, with a pH 5.6 and $7.5 \mathrm{~g} \mathrm{~L}^{-1}$ agar. From this medium, $5 \mathrm{~mL}$ were extracted and distributed in $18 \mathrm{~mm} \times 150 \mathrm{~mm}$ tubes and then sterilized for $20 \mathrm{~min}$ at $1.5 \mathrm{MPa}$. Nodal cuttings were removed from each plantlets, which were selected for the study, and planted in the MS culture media. This material was kept in a growth chamber at $20^{\circ} \mathrm{C}$, with a $16: 8 \mathrm{~h}$ photoperiod and around $50 \mathrm{~W} \mathrm{~m} \mathrm{~m}^{2}$ provided by cool white fluorescent light.

\section{Treatments}

Eight culture media were prepared for the treatments, some of them with osmotic regulators as sorbitol or mannitol at different concentrations (Table 1). All the culture media composition consisted in a base medium with complete MS medium $4.43 \mathrm{~g} \mathrm{~L}^{-1}$, sucrose $27.5 \mathrm{~g} \mathrm{~L}^{-1}$, agar $7.5 \mathrm{~g} \mathrm{~L}^{-1}$ and $\mathrm{pH}$ adjusted to 5.6. Treatments varied in medium composition by addition of growth regulators or osmotic regulators to the base medium in the following way. Medium 1: Base medium 
Table 1. Culture media employed and formulation for in vitro growing of Chilotanum potato explants.

\begin{tabular}{|c|c|c|c|c|c|c|}
\hline $\begin{array}{l}\text { Treatments } \\
\text { (medium) }\end{array}$ & MS & Sucrose & Sorbitol & Mannitol & Agar & $\begin{array}{c}\text { Gibberellic } \\
\text { acid }\end{array}$ \\
\hline & & & $-\mathrm{g} \mathrm{L}^{-1}$ & & - & $\mathrm{mg} \mathrm{L}^{-1}$ \\
\hline 1 & 4.43 & 27.5 & - & - & 7.5 & - \\
\hline 2 & 4.43 & 27.5 & - & - & 7.5 & 0.2 \\
\hline 3 & 4.43 & 27.5 & 20 & - & 7.5 & - \\
\hline 4 & 4.43 & 27.5 & 40 & - & 7.5 & - \\
\hline 5 & 4.43 & 27.5 & 60 & - & 7.5 & - \\
\hline 6 & 4.43 & 27.5 & - & 20 & 7.5 & - \\
\hline 7 & 4.43 & 27.5 & - & 40 & 7.5 & - \\
\hline 8 & 4.43 & 27.5 & - & 60 & 7.5 & - \\
\hline
\end{tabular}

without osmotic regulator. Medium 2: Base medium and gibberellic acid $0.2 \mathrm{mg} \mathrm{L}^{-1}$. Medium 3: Base medium and sorbitol $20 \mathrm{~g} \mathrm{~L}^{-1}$. Medium 4: Base medium and sorbitol $40 \mathrm{~g} \mathrm{~L}^{-1}$. Medium 5: Base medium and sorbitol $60 \mathrm{~g} \mathrm{~L}^{-1}$. Medium 6: Base medium and mannitol $20 \mathrm{~g} \mathrm{~L}^{-1}$. Medium 7: Base medium and mannitol $40 \mathrm{~g} \mathrm{~L}^{-1}$. Medium 8: Base medium and mannitol $60 \mathrm{~g} \mathrm{~L}^{-1}$. Gibberelic acid was added to medium 2 because is usually used to promote shoot elongation for potato in vitro culture (Shahriyar et al., 2015). Nodal cuttings were extracted from the mother plants and were introduced into the culture media for each test tube. Ten replicates were treated for each genotype in one medium, making a total of 80 in vitro plants per genotype and finally 240 plants under study. All treatments were applied in three genotypes. The experimental design was completely randomized with 10 replicates. All treated plant material was kept in a growth chamber at $20^{\circ} \mathrm{C}$ with $16: 8$ h photoperiod.

The height of in vitro plantlets, mortality, proportion of senescent leaves, vitrification, and diverse abnormalities were evaluated weekly.

\section{Monitoring of plant growing}

A simple visual measurement with the help of a ruler through the walls of the test tubes was obtained to evaluate plant height. The determination of the number of roots was made counting developed roots through the walls of the tubes. All other criteria were measured through observation. All the measured and observed data were registered in a form that contained all the evaluated criteria. Weekly monitoring was carried out from week 1 to week 17, with the exception of week 13. After this period, weeks 22, 24, 27, 29, 32, and 36 were checked once a week. A record of data analysis in Excel was carried out in each analysis. Percentage of mortality, senescence and browning were recorded and expressed as percentage of explants in such condition for each media tested.

\section{Analysis of data}

The growth rates of the plants were calculated with the Gompertz growth model (Zwietering et al., 1990), normally used to model biological systems such as plant growth.

\section{Kinetic modeling}

Considering the height of the samples $(H, \mathrm{~cm})$ growing in time $(t)$, the following model equation was used (all kinetics showed sigmoidal behavior):

$$
\left.H=\mathrm{A} * \mathrm{e}^{-\mathrm{e}}\left(\frac{k * \mathrm{e}}{\mathrm{A}}\right) *(f-t)+1\right)
$$

This equation is based on the Gompertz growth model, which gives the possibility to calculate three parameters that describe a particular sigmoidal kinetic. The maximum specific growth rate $k\left(\mathrm{~cm} \mathrm{wk}^{-1}\right)$ and defined as the tangent in the inflection point; the lag time or delay phase $f$ (wk) defined as the x-axis intercept of this tangent; and, $A$ the maximal value reached (Zwietering et al., 1990). A kinetic rate for each treatment was calculated, fitting the data to the Equation [1], with a nonlinear least squares regression.

Additionally, the variables "final length of shoot after $36 \mathrm{wk}$ " and "time when maximum length is reached" measured at the end of the experiment were analyzed by factorial ANOVA test after transformation of data to natural logarithm. 
Mean comparison between treatments were performed by Tukey test at 0.05 significance. The statistical package InfoStat (Universidad Nacional de Córdoba, Córdoba, Argentina) was employed.

\section{RESULTS}

The kinetic behavior of one selected sample from Medium 1 of the genotype $\mathrm{CO}$ and its corresponding fitted Equation [1] is shown in Figure 1.

All kinetics curves obtained showed the same tendency. It has to do with a sigmoidal curves behavior, with an initial delay phase, followed by the exponential phase and, finally, with a stable one. The delay phase (f) value and the kinetic rate for all treatments for $\mathrm{CO}$ are showed in the Table 2.

In Figure 2, the kinetic behavior of one selected sample of Medium 8 of the genotype IN and its corresponding fitted Equation [1] is shown. The f value and the kinetic rate for all treatments for IN are showed in the Table 3 .

In Figure 3, the kinetic behavior of one selected sample from Medium 5 of the genotype NA and its corresponding fitted Equation [1] is shown. The $\mathrm{f}$ value and the kinetic rate for all treatments for NA data are showed in the Table 4.

There is a clear tendency of the $\mathrm{k}$ value to decrease when the concentration of the osmotic regulators are higher. Media 3, 4, 5, 6, 7, and 8, with 20,40, and $60 \mathrm{~g} \mathrm{~L}^{-1}$ sorbitol and mannitol, respectively, showed significantly lower rate of growing than media without growth regulators. In MS medium without osmotic active compounds the lower rate of shoot elongation (k) was 1.12 for IN and the highest rate was $1.45 \mathrm{~cm} \mathrm{wk}^{-1}$ for NA with $0 \%$ mortality. The addition of gibberelic

Figure 1. Fitting the Growth model (Gompertz's equation) to R12-15 Clon Amarillo CO in treatment 1 data.

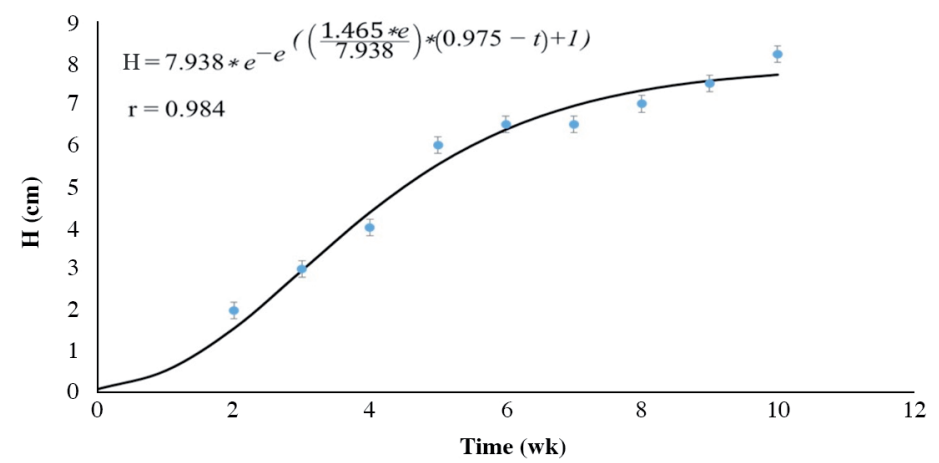

Treatment 1: Complete MS medium $4.43 \mathrm{~g} \mathrm{~L}^{-1}$, sacarose $27.5 \mathrm{~g} \mathrm{~L}^{-1}$, and agar $7.5 \mathrm{~g} \mathrm{~L}^{-1}$ without sorbitol or mannitol.

$\mathrm{H}$ : Plant height $(\mathrm{cm})$ as indicated in Equation [1].

Table 2. Delay phase (f value) and rate of shoot elongation (k) with different media, calculated from fitting the Growth model (Gompertz's equation). Data for potato genotype R12-15 Clon 18 Amarillo (CO).

\begin{tabular}{lcc}
\hline Treatments (medium) & f value & $\mathrm{k}$ \\
\hline & $\mathrm{wk}$ & $\mathrm{cm} \mathrm{wk}^{-1}$ \\
1 & $0.899 \mathrm{a}$ & $1.443 \mathrm{a}$ \\
2 & $0.821 \mathrm{a}$ & $1.117 \mathrm{a}$ \\
3 & $5.738 \mathrm{~b}$ & $0.550 \mathrm{~b}$ \\
4 & $1.666 \mathrm{c}$ & $0.36 \mathrm{bc}$ \\
5 & $3.505 \mathrm{~d}$ & $0.095 \mathrm{c}$ \\
6 & $0 \mathrm{e}$ & $0.256 \mathrm{bc}$ \\
7 & $0 \mathrm{e}$ & $0.112 \mathrm{bc}$ \\
8 & $0.632 \mathrm{a}$ & $0.042 \mathrm{c}$ \\
Mean standard deviation (10 replicates) & $( \pm 0.210)$ & $( \pm 0.181)$ \\
Mean r coefficient & $0.988 \pm 0.006$ & $0.988 \pm 0.006$
\end{tabular}

*A different letter is indicative of a significant difference according to Tukey test at $95 \%$ of confidence. For treatments details, see Table 1 . 
Figure 2. Fitting the Growth model (Gompertz's equation) to CH6-13 Sofía IN in treatment 8 data.

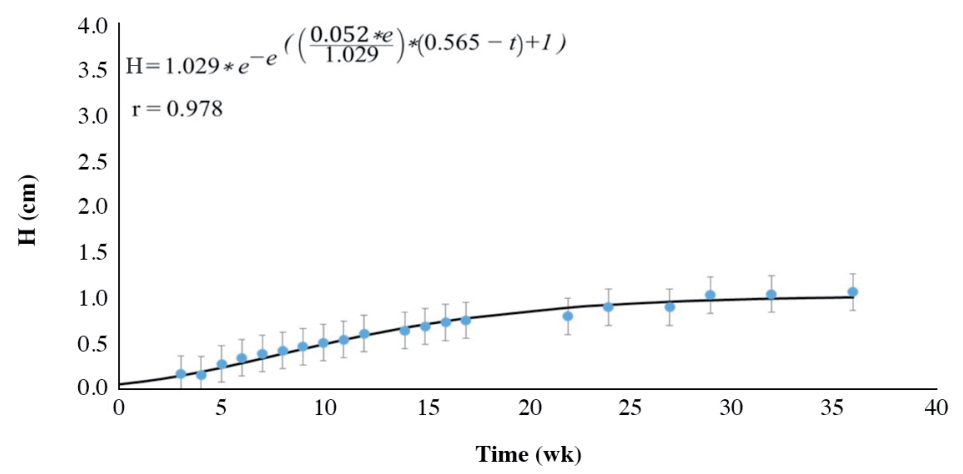

Treatment 8: Complete MS medium $4.43 \mathrm{~g} \mathrm{~L}^{-1}$, sacarose $27.5 \mathrm{~g} \mathrm{~L}^{-1}$, agar $7.5 \mathrm{~g} \mathrm{~L}^{-1}$, and mannitol $60 \mathrm{~g} \mathrm{~L}^{-1}$.

$\mathrm{H}$ : Plant height $(\mathrm{cm})$ as indicated in Equation [1].

Table 3. Delay phase (f value) and rate of shoot elongation (k) with different media, calculated from fitting the Growth model (Gompertz's equation). Data for genotype CH6-13 Sofía (IN).

\begin{tabular}{lcc}
\hline Treatments (medium) & $\mathrm{f}$ value & $\mathrm{k}$ \\
\hline & $\mathrm{wk}$ & $\mathrm{cm} \mathrm{wk}^{-1}$ \\
1 & $1.821 \mathrm{a}$ & $1.115 \mathrm{a}$ \\
2 & $1.341 \mathrm{a}$ & $1.017 \mathrm{ab}$ \\
3 & $6.580 \mathrm{~b}$ & $0.580 \mathrm{~b}$ \\
4 & $4.130 \mathrm{c}$ & $0.424 \mathrm{bc}$ \\
5 & $1.902 \mathrm{a}$ & $0.106 \mathrm{c}$ \\
6 & $0.811 \mathrm{~d}$ & $0.161 \mathrm{bc}$ \\
7 & $0.000 \mathrm{e}$ & $0.065 \mathrm{c}$ \\
8 & $0.566 \mathrm{de}$ & $0.052 \mathrm{c}$ \\
Mean standard deviation (10 replicates) & $( \pm 0.205)$ & $( \pm 0.176)$ \\
Mean r coefficient & $0.992 \pm 0.007$ & $0.992 \pm 0.007$ \\
\hline
\end{tabular}

*A different letter is indicative of a significant difference according to Tukey test at $95 \%$ of confidence. For treatments details, see Table 1.

acid $0.2 \mathrm{mg} \mathrm{L}^{-1}$ in medium 2 (used to promote faster shoot elongation) did not produce significant differences with respect to medium 1. In media supplemented with 20,40 , and $60 \mathrm{~g} \mathrm{~L}^{-1}$ sorbitol, $\mathrm{k}$ value ranged between $0.58-0.35,0.42-0.27$ and 0.09-0.05 $\mathrm{cm} \mathrm{wk}^{-1}$, respectively, where the highest values correspond to genotype IN and the lowest values were always showed by NA. Mortality was $0 \%, 13 \%$, and $26 \%$ for such treatments in average for the three genotypes.

In media supplemented with mannitol, $\mathrm{k}$ value ranged between $0.14-0.25,0.065-0.11$ and $0.042-0.068 \mathrm{~cm} \mathrm{wk}^{-1}$ with $3 \%, 6 \%$, and $26 \%$ mortality for 20,40, and $60 \mathrm{~g} \mathrm{~L}^{-1}$, respectively (Tables 2, 3, 4 and 6). Highest and lowest values were reached indistinctly by the three genotypes.

The composition of culture medium factor had a significant effect on the variable final shoot length $(\mathrm{p}<$ 0.01 ). The media number 8 and 5 showed the lower growth of the explants and media 1,2, and 3 the higher shoots. The media 4, 6, and 7 displayed less growth not reaching the whole capacity of the container allowing a more extended period before transferring the explant to a new tube (Table 5). Media 4 and 6 caused low mortality and abnormalities (Table 6) in the growing explant with a significant reduction of growing rate $(5.65$ and $4.29 \mathrm{~cm}$ length after $36 \mathrm{wk}$, average for three genotypes) (Table 5). Medium 3 (growing rate $7.96 \mathrm{~cm}$ ) produced no mortality with some reduction of final growth at the end of the experiment but nonsignificant with respect to media $1(9.5 \mathrm{~cm})$ and $2(9.0 \mathrm{~cm})$ without osmotic retardant.

In the same way, the Genotype factor had also a significant effect in such variable. There was a significant Medium composition $\times$ Genotype interaction $(\mathrm{p}<0.01)$. Genotype NA showed less growth with respect to the other genotypes (4.45 cm length for the average of all the media tested) whereas genotypes IN and CO reached 5.34 and $5.52 \mathrm{~cm}$ with nonsignificant difference between them. 
Figure 3. Fitting the Growth model (Gompertz's equation) to CH9-1 Ojos Sarcos de Cahuala NA in treatment 5 data.

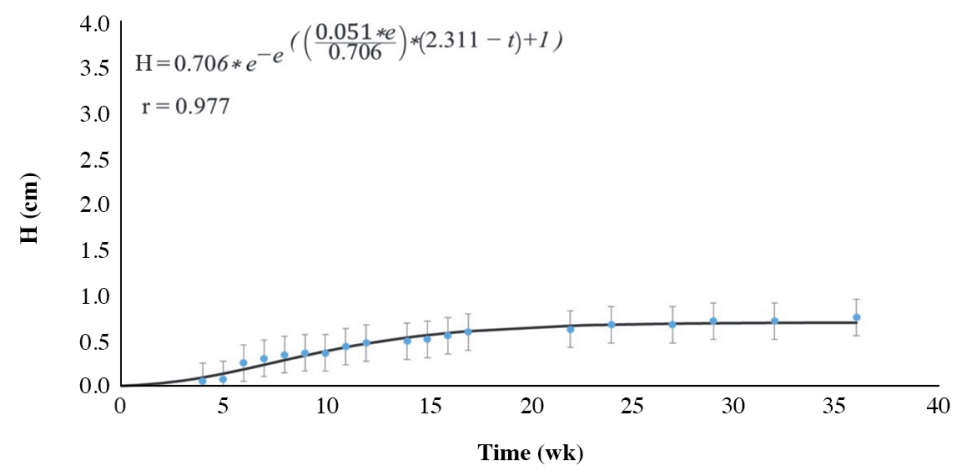

Treatment 5: Complete MS medium $4.43 \mathrm{~g} \mathrm{~L}^{-1}$ sacarose $27.5 \mathrm{~g} \mathrm{~L}^{-1}$, agar $7.5 \mathrm{~g} \mathrm{~L}^{-1}$, and sorbitol $60 \mathrm{~g} \mathrm{~L}^{-1}$.

$\mathrm{H}$ : Plant height $(\mathrm{cm})$ as indicated in Equation [1].

Table 4. Delay phase (f value) and rate of shoot elongation (k) with different media, calculated from fitting the Growth model (Gompertz's equation). Data for genotype CH9-1 Ojos Sarcos de Cahuala (NA).

\begin{tabular}{lcc}
\hline Treatments (medium) & f value & $\mathrm{k}$ \\
\hline & $\mathrm{wk}$ & $\mathrm{cm} \mathrm{wk}^{-1}$ \\
1 & $1.151 \mathrm{a}$ & $1.475 \mathrm{a}$ \\
2 & $0.898 \mathrm{a}$ & $1.079 \mathrm{a}$ \\
3 & $3.537 \mathrm{~b}$ & $0.352 \mathrm{~b}$ \\
4 & $2.451 \mathrm{~cd}$ & $0.279 \mathrm{~b}$ \\
5 & $2.311 \mathrm{c}$ & $0.051 \mathrm{~b}$ \\
6 & $3.580 \mathrm{~d}$ & $0.143 \mathrm{~b}$ \\
7 & $0.000 \mathrm{e}$ & $0.077 \mathrm{~b}$ \\
8 & $0.359 \mathrm{e}$ & $0.068 \mathrm{~b}$ \\
Mean standard deviation (10 replicates) & $( \pm 0.247)$ & $( \pm 0.190)$ \\
Mean r coefficient & $0.981 \pm 0.022$ & $0.988 \pm 0.022$ \\
\hline
\end{tabular}

*A different subscript letter is indicative of a significant difference according to Tukey test at $95 \%$ of confidence. For treatments details, see Table 1.

Table 5. Final length of shoot after $36 \mathrm{wk}$ in eight culture media tested. Mean of 10 replicates among the three genotypes.

\begin{tabular}{ccccccc}
\hline $\begin{array}{l}\text { Treatments } \\
\text { (medium) }\end{array}$ & $\mathrm{n}$ & $\begin{array}{c}\text { Final } \\
\text { length }\end{array}$ & $\begin{array}{c}\text { Standard } \\
\text { error }\end{array}$ & CV & Min & Max \\
\hline 1 & 30 & $9.50 \mathrm{a}$ & 0.14 & 8.05 & 8.00 & 11.00 \\
2 & 29 & $9.00 \mathrm{a}$ & 0.22 & 13.02 & 5.00 & 11.00 \\
3 & 30 & $7.96 \mathrm{a}$ & 0.36 & 24.62 & 3.90 & 10.30 \\
4 & 26 & $5.65 \mathrm{~b}$ & 0.50 & 45.33 & 0.70 & 10.30 \\
5 & 22 & $1.48 \mathrm{~cd}$ & 0.23 & 72.57 & 0.30 & 3.50 \\
6 & 29 & $4.29 \mathrm{~b}$ & 0.31 & 38.71 & 1.00 & 8.10 \\
7 & 28 & $1.70 \mathrm{c}$ & 0.16 & 48.21 & 0.80 & 4.00 \\
8 & 22 & $1.08 \mathrm{~d}$ & 0.10 & 41.30 & 0.30 & 1.80 \\
\hline
\end{tabular}

A different letter is indicative of a significant difference according to Tukey test at $95 \%$ of confidence.

*For treatments details, see Table 1 .

Over the variable time when maximum length is reached factor, medium composition had a significant effect $(\mathrm{p}<0.01)$. Genotype did not show a significant influence on this variable; however, there was an interaction between both factors. In media 1 and 2 the explants reached the whole capacity in the flask in 9.87 and $11.17 \mathrm{wk}$, with $9 \mathrm{~cm}$ length reaching the top of the container (Table 7). While in medium 3, the explants completed the whole capacity of the container in $24 \mathrm{wk}$ with no mortality or browning of the explants. In media 4, 5, 6, 7, and 8 the growing of the explants never achieved the 
Table 6. Percentage of mortality, senescence and browning in average among three genotypes for eight culture media tested.

\begin{tabular}{|c|c|c|c|c|c|c|}
\hline $\begin{array}{l}\text { Treatments } \\
\text { (medium) }\end{array}$ & Variable & Mean & $\begin{array}{c}\text { Standard } \\
\text { error }\end{array}$ & $\mathrm{CV}$ & Min & $\operatorname{Max}$ \\
\hline 1 & Mortality, \% & 0.00 & 0.00 & sd & 0.00 & 0.00 \\
\hline 2 & Mortality, \% & 3.33 & 3.33 & 173.2 & 0.00 & 10.00 \\
\hline 3 & Mortality, \% & 0.00 & 0.00 & sd & 0.00 & 0.00 \\
\hline 4 & Mortality, \% & 13.33 & 6.67 & 86.6 & 0.00 & 20.00 \\
\hline 5 & Mortality, \% & 26.67 & 17.64 & 114.5 & 0.00 & 60.00 \\
\hline 6 & Mortality, \% & 3.33 & 3.33 & 173.2 & 0.00 & 10.00 \\
\hline 7 & Mortality, \% & 6.67 & 6.67 & 173.2 & 0.00 & 20.00 \\
\hline 8 & Mortality, \% & 26.67 & 16.67 & 108.3 & 10.00 & 60.00 \\
\hline 1 & Senescence, $\%$ & 0.00 & 0.00 & sd & 0.00 & 0.00 \\
\hline 2 & Senescence, $\%$ & 0.00 & 0.00 & sd & 0.00 & 0.00 \\
\hline 3 & Senescence, $\%$ & 0.00 & 0.00 & sd & 0.00 & 0.00 \\
\hline 4 & Senescence, $\%$ & 30.00 & 20.00 & 115.47 & 10.00 & 70.00 \\
\hline 5 & Senescence, $\%$ & 6.67 & 3.33 & 86.60 & 0.00 & 10.00 \\
\hline 6 & Senescence, $\%$ & 13.33 & 6.67 & 86.60 & 0.00 & 20.00 \\
\hline 7 & Senescence, $\%$ & 6.67 & 6.67 & 173.21 & 0.00 & 20.00 \\
\hline 8 & Senescence, $\%$ & 16.67 & 8.82 & 91.65 & 0.00 & 30.00 \\
\hline 1 & Browning, \% & 0.00 & 0.00 & sd & 0.00 & 0.00 \\
\hline 2 & Browning, \% & 0.00 & 0.00 & sd & 0.00 & 0.00 \\
\hline 3 & Browning, \% & 0.00 & 0.00 & sd & 0.00 & 0.00 \\
\hline 4 & Browning, \% & 30.00 & 30.00 & 173.2 & 0.00 & 90.00 \\
\hline 5 & Browning, \% & 0.00 & 0.00 & sd & 0.00 & 0.00 \\
\hline 6 & Browning, \% & 3.33 & 3.33 & 173.2 & 0.00 & 10.00 \\
\hline 7 & Browning, \% & 0.00 & 0.00 & $\mathrm{sd}$ & 0.00 & 0.00 \\
\hline 8 & Browning, \% & 0.00 & 0.00 & $\mathrm{sd}$ & 0.00 & 0.00 \\
\hline
\end{tabular}

For treatments details, see Table 1.

sd : Without deviation.

Table 7. Time when explants reached the maximum length in eight culture media tested. Mean of 10 replicates among the three genotypes.

\begin{tabular}{cccc}
\hline $\begin{array}{l}\text { Treatments } \\
\text { (medium) }\end{array}$ & Time & $\mathrm{n}$ & $\begin{array}{c}\text { Standard } \\
\text { error }\end{array}$ \\
\hline & wk & & \\
1 & $9.87 \mathrm{a}$ & 30 & 0.51 \\
2 & $11.17 \mathrm{a}$ & 29 & 0.52 \\
3 & $24.60 \mathrm{~b}$ & 30 & 0.51 \\
4 & $33.75 \mathrm{c}$ & 26 & 0.56 \\
8 & $36.00 \mathrm{c}$ & 22 & 0.65 \\
7 & $36.00 \mathrm{c}$ & 28 & 0.54 \\
6 & $36.00 \mathrm{c}$ & 29 & 0.52 \\
5 & $36.00 \mathrm{c}$ & 22 & 0.65 \\
\hline
\end{tabular}

A different letter is indicative of a significant difference at $95 \%$ of confidence. $\mathrm{n}$ varies across the media because mortality of the explants in some of them. For treatment details see Table 1.

length to complete the capacity of the flask (10 cm tall) in $36 \mathrm{wk}$ of culture. However, in these media there was mortality, browning and senescence of the explants. Percentage of mortality in media 4, 5, 6, 7, and 8 reached 13\%, 26\%, 3\%, 6\%, and $26 \%$, respectively (Table 6).

\section{DISCUSSION}

Slow growth storage (also called 'medium-term conservation' or 'minimal growth storage') is based on the reduction of the metabolic activity (i.e., growth rate) of in vitro shoot cultures by maintaining them on 'modified culture conditions'. The consequence is the extension of the intervals between periodic subcultures (from once in a month to once per year or more, depending on the species) of in vitro shoot cultures without negatively affecting their viability and regrowth potential in post-conservation. In this way, manual labor, cost of tissue culture applications and the risk of contamination during periodic transfers are reduced too (Ozudogru et al., 2017). 
Both osmotic active compounds, sorbitol and mannitol, produced a reduced growth in the three Chilean native genotypes. The purpose of the treatments applied in this work was the induction of the controlled osmotic stress for delay conservation period. As the concentration increased from 20 to $60 \mathrm{~g} \mathrm{~L}^{-1}$ the growth rate was diminished. However, the percentage of mortality of explants was higher with $60 \mathrm{~g} \mathrm{~L}^{-1}$, either in sorbitol or mannitol reaching $26.6 \%$ with such concentration. An ideal osmotic agent would be non-toxic, non-penetrating yet reducing the osmotic potential of the medium (Bündig et al., 2016). Increases in acyclic polyols such as mannitol and sorbitol have been observed in response to stress in many plants. These compounds can act as osmoregulators as well as oxygen radical scavengers. Osmotic adjustment might include metabolites such as proline, betaine, mannitol and sorbitol (Moradi et al., 2017). At concentration of $60 \mathrm{~g} \mathrm{~L}^{-1}$ mannitol or sorbitol is evident that plant was submitted to toxic and stressful conditions. Works in proteomics analysis of in vitro grown plants exposed to mannitol indicated that mechanisms that mediate responses to salt- and mannitol-induced stress were different and dependent on tissue type (Balen et al., 2013). Tissues exposed to the highest concentrations of both stressors showed signs of protein degradation, which was most pronounced in tissues treated with $700 \mathrm{mM}$ mannitol. Exposure to mannitol down-regulated the expression of 11 proteins when compared to control tissue. Analysis of responsiveness of callus proteins to either salt or mannitol revealed that mannitol treatment induced changes in expression of $60 \%$ proteins, among which the equal number was up- and down-regulated. Osmotic stress provoked by mannitol induced the synthesis of 12 proteins while the same treatment decreased the synthesis of 16 proteins. Energy category was represented with $22 \%$ of all identified proteins among which two out of four proteins were up-regulated (both identified as partial RuBisCO large subunits) in response to salinity as well as mannitol. Metabolism as well as oxidation and detoxification classes were represented with $11 \%$ of identified proteins out of which three were mannitol responsive (alpha amylase, cytosolic glyceraldehyde-3 phosphate dehydrogenase and catalase) and mostly upregulated. Down-regulation of proteins involved in cell protection suggests the inability of tissues to activate protective processes against salinity and osmotic stress. However, unique flexibility of plant carbohydrate and energy metabolism may help in coping with unavoidable environmental stresses (Rogic et al., 2015). Mannitol can induce an effect similar to drought conditions in plants (Chutipaijit, 2016).

The treatments of $20 \mathrm{~g} \mathrm{~L}^{-1}$ with sorbitol produced no mortality and no abnormalities (senescence or browning) with reduction in growth rate (Tables 2, 3, 4 and 6) in the three genotypes under study. Although nonsignificant reduction in final length at the end of the experiments was found, the significant reduction of rate of growing $\left(\mathrm{cm} \mathrm{wk}^{-1}\right)$ shows a successful result in the extension of the intervals to reach the complete capacity of the container and increase the period between periodic subcultures of in vitro shoot cultures without negatively affecting their viability. With mannitol some mortality was showed (3.3\%). Thinking in a more significant retardation of growing, concentrations of $40 \%$ of sorbitol and mannitol seems to be useful with acceptable levels of mortalities and abnormalities (13\% and 6\% mortality in sorbitol and mannitol, respectively) but this will depend on the quantity of available plant material. In case of scarce plant material or severely endangered accessions it could not be recommended to use $40 \mathrm{~g} \mathrm{~L}^{-1}$ because of the probability to lose some plants in the process. As an alternative or complement to the use of osmotically active compounds (e.g., mannitol and sorbitol), the reduction of metabolic activity can be achieved by using cold storage, growth retardants (e.g., chlorocholine chloride and abscisic acid), osmotically or reduced mineral concentration in the culture medium (Corredoira et al., 2017). Genotype and quality of the shoot cultures, as well as the sucrose concentration in the culture medium and the use of various types of culture containers, differing in their gas permeability are among other factors affecting markedly the maximum storage period of shoot cultures (Ozudogru et al., 2017). These other factors can be tested in further experiments to optimize the protocol of medium term storage for Chilean native potatoes, however this work is very useful to provide a clear description, modelling of growing and behavior under osmotic actively compounds to delay the conservation period before subculturing in order to help and to ease the conservation process of this type of germplasm.

Sorbitol, a six-C sugar alcohol, serves as a primary photosynthate, and translocation and storage substance in plants (Singh et al., 2015). Lemos and Baker (1998) showed that sorbitol induced shoot initiation and callus formation on internodal explants, but mannitol did not. These authors suggested that the roles of sorbitol may extend beyond those of a $\mathrm{C}$ source or osmotic regulator. It was suggested that sorbitol might alter molecular and physiological processes via chemical signaling, rather than by its role as a $C$ source or osmotic regulator (Feng et al., 2011). In this research, at the same concentration, the growing in presence of sorbitol was faster than in mannitol, with significant differences in final length and time in reaching the maximum length. This suggests that sorbitol has some effects that allow or even promote some type of growing of cellular divisions, whereas mannitol is more restrictive to plant growth over Chilean native germplasm. 
Bündig et al. (2016) demonstrate that two potato genotypes, divergently reacting to $0.2 \mathrm{M}$ sorbitol in vitro act differently with the applied stress. The authors suggest that the tolerant genotype might have adapted to the applied stress in vitro after $11 \mathrm{~d}$, whereas the sensitive genotype still suffers from osmotic stress and takes countermeasures in building up new metabolites and proteins for protection. It was found that both genotypes displayed an uptake sorbitol. But it is unknow if it is also metabolized or only stored in potatoes (Bündig et al., 2016). In our work there were differences due the genotype factor in response to the treatments but the magnitude of the differences in growing are not as marked as the differences produced by the concentration of osmotic agent. Only the variable final length of shoot was affected by the genotype factor. The behavior of the explants was similar over the three genotypes tested as to reference to time when maximum length is reached ( $\mathrm{p}>0.05$ ) and growth rates changes in the different media treatments (Tables 2, 3, 4 and Figures, 1, 2,3).

The use of different media provides alternatives to address the in vitro culture of Chilean native potato germplasm. Depending on the purpose of the in vitro culture, different speed of growing could be needed to achieve the objectives of the different steps of germplasm management. For example, to obtain a fast growth of plant material before massive transplant of plants in greenhouses or even field conditions, the medium 1 or 2 (Table 1) can be applied. The rates of growth described in this study can be used to predict shoot elongation, to control timing of propagation and to calculate culture media, flask, hand labor, necessary human resources and the number of plants or multiplication units potentially reachable in some period. For another step of germplasm management, in case of a more prolonged conservation, with no immediate requirement of multiplication, media 3,4,6, and 7 can be used to reduce resources expenses and to keep potato material for longer periods as slow growth storage. The curves of growth and rates of shoot elongation can be applied to elaborate a conservation and planning strategy for the assignment of resources and possibilities of conservation times.

\section{CONCLUSIONS}

The addition of mannitol and sorbitol to culture media allows to reduce the rate of growth in Chilotanum potato germplasm. The rate of growing is drastically affected by the presence of these compound and concentration in the culture media. Sorbitol at $20 \mathrm{~g} \mathrm{~L}^{-1}$ is appropriated for medium term storage of the mentioned germplasm with significative reduction of rate of growing without mortality or abnormalities. This protocol can be used for conservation of collections of Chilean potatoes. An even higher reduction in growing can be achieved with 40 or $60 \mathrm{~g} \mathrm{~L}^{-1}$ sorbitol or mannitol added in the culture medium but mortality start to appear and it can reach $26 \%$ in the higher concentration for both regulators, such conditions are not recommended. Improvements of this protocol can be achieved by the study of low temperature or lower intensity light treatments in further experiments.

From this study, curves to predict in vitro growth over time for Chilotanum germplasm in different culture media are available for using in active potato bank operation.

\section{ACKNOWLEDGEMENTS}

We thank the Chilean Ministry of Agriculture and the Project "Conservación de Recursos Genéticos" 501453-70 for funding and support.

\section{REFERENCES}

Balen, B., Tkalec, M., Rogic, T., Simac, M., Stefanic, P., Roncevic, S., et al. 2013. Effects of iso-osmotic NaCl and mannitol on growth, proline content, and antioxidant defense in Mammillaria gracilis Pfeiff. in vitro-grown cultures. In Vitro Cellular and Developmental Biology - Plant 49:421-432.

Bündig, C., Blume, C., Peterhänsel, C., and Winkelmann, T. 2016. Changed composition of metabolites in Solanum tuberosum subjected to osmotic stress in vitro: Is sorbitol taken up? Plant Cell, Tissue and Organ Culture 127:195-206. https://doi. org/10.1007/s11240-016-1042-1.

Castañeda-Álvarez, N.P., de Haan, S., Juárez, H., Khoury, C.K., Achicanoy, H.A., Sosa, C.C., et al. 2015. Ex situ conservation priorities for the wild relatives of potato (Solanum L. Section Petota). PLOS ONE 10(4):e0122599. doi:10.1371/journal.pone.0122599.

Chutipaijit, S. 2016. Changes in physiological and antioxidant activity of indica rice seedlings in response to mannitol induced osmotic stress. Chilean Journal of Agricultural Research 76:455-462. 
Contreras A., and Castro, I. 2008. Catálogo de variedades de papas nativas de Chile. 234 p. Universidad Austral de Chile, Valdivia, Chile.

Corredoira, E., Martínez, M., Cernadas, M., and San José, M. 2017. Application of biotechnology in the conservation of the Genus Castanea. Forests 8:394. doi:10.3390/f8100394.

Feng, X., Zhao, P., Hao, J., Hu, J., Kang, D., and Wang, H. 2011. Effects of sorbitol on expression of genes involved in regeneration of upland rice (Oryza sativa L.) Plant Cell, Tissue and Organ Culture 106:455-463.

Gopal, J., and Chauhan, N. 2010. Slow growth in vitro conservation of potato germplasm at low temperature. Potato Research 53:141-149.

Hawkes, J.G. 1990. The potato: evolution, biodiversity and genetic resources. 259 p. Belhaven Press, London, UK.

Khoury, C.K., Bjorkmanc, A., Dempewolfd, H., Ramirez-Villegas, J., Guarinof, L., Jarvisa, A., et al. 2014. Increasing homogeneity in global food supplies and the implications for food security. Proceedings of the National Academy of Sciences of the United States of America 111(11):4001-4006.

Lemos, E.E.P., and Baker, D.A. 1998. Shoot regeneration in response to carbon source on internodal explants of Annona muricata L. Plant Growth Regulation 25:105-112.

Mohapatra, P., and Batra, V.K. 2017. Tissue culture of potato (Solanum tuberosum L.): A review. International Journal of Current Microbiology and Applied Sciences 6(4):489-495.

Moradi, P., Ford-Lloyd, B., and Pritchard, J. 2017. Metabolomic approach reveals the biochemical mechanisms underlying drought stress tolerance in thyme. Analytical Biochemistry 527:49-62.

Muñoz, M., Folch, C., Rodriguez, F., Kalazich, J., Orena, S., Santos, J., et al. 2016. Genotype number and allelic diversity overview in the national collection of Chilean potatoes. Potato Research 59:227-240.

Murashige, T., and Skoog, F. 1962. A revised medium for rapid growth and bio assays with tobacco tissue cultures. Physiologia Plantarum 15:473-497.

Ozudogru, E., Benelli, C., Dradi, G., and Lambardi, M. 2017. Effect of culture container and carbohydrate content on in vitro slow growth storage of the cherry rootstock 'Gisela 5'. Acta Physiologiae Plantarum 39:94. doi:10.1007/s11738-017-2372-2.

Rogic, T., Horvatic, A., Tkalec, M., Cindric, M., and Balen, B. 2015. Proteomic analysis of Mammillaria gracilis Pfeiff. in vitro-grown cultures exposed to iso-osmotic $\mathrm{NaCl}$ and mannitol. Plant Cell, Tissue and Organ Culture 122:127-146. doi:10.1007/s11240-015-0756-9.

Shahriyar, S., Akram, S., Khan, K., Miya, F., and Sarkar, A. 2015. In vitro plant regeneration of potato (Solanum tuberosum L.) at the rate of different hormonal concentration. Asian Journal of Medical and Biological Research 1(2):297-303.

Singh, M., Kumar, J., Singh, S., Singh, V., and Prasad, S. 2015. Roles of osmoprotectants in improving salinity and drought tolerance in plants: a review. Reviews in Environmental Science and Bio/Technology 14:407-426.

Spooner, D., Ghislain, M., Simon, R., Jansky, S., and Gavrilenko, T. 2014. Systematics, diversity, genetics, and evolution of wild and cultivated potatoes. Botanical Review 80:283-383.

Zwietering, M., Jongenburger, I., Rombouts, M., and van Riet, K. 1990. Modelling of the bacterial growth curve. Applied and Environmental Microbiology 56(6):1875-1881. 